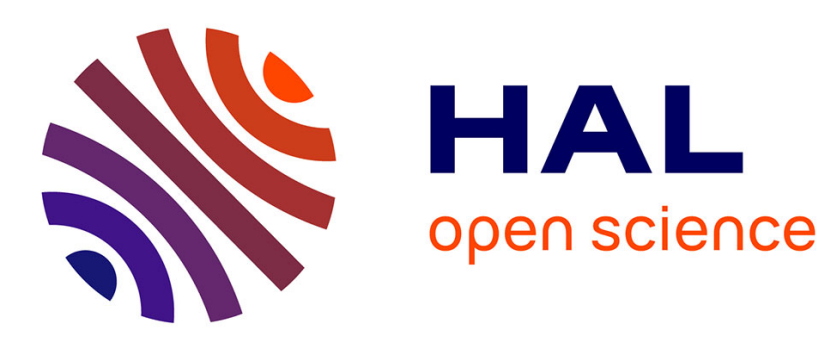

\title{
Trajectories from today's WWW to a powerful educational infrastructure
}

Jeremy Roschelle, Roy D. Pea

\section{To cite this version:}

Jeremy Roschelle, Roy D. Pea. Trajectories from today's WWW to a powerful educational infrastructure. Educational Researcher, 1999, 28(5), pp.22-25. hal-00190605

\section{HAL Id: hal-00190605 \\ https://telearn.archives-ouvertes.fr/hal-00190605}

Submitted on 23 Nov 2007

HAL is a multi-disciplinary open access archive for the deposit and dissemination of scientific research documents, whether they are published or not. The documents may come from teaching and research institutions in France or abroad, or from public or private research centers.
L'archive ouverte pluridisciplinaire $\mathbf{H A L}$, est destinée au dépôt et à la diffusion de documents scientifiques de niveau recherche, publiés ou non, émanant des établissements d'enseignement et de recherche français ou étrangers, des laboratoires publics ou privés. 


\title{
TRAJECTORIES FROM TODAY'S WWW TO A POWERFUL EDUCATIONAL INFRASTRUCTURE
}

\author{
Jeremy Roschelle and Roy D. Pea \\ Center for Innovative Learning Technologies \\ SRI International
}

(Submitted to Educational Researcher, Research News and Comment)

Three previous Research News and Comment articles in Educational Researcher have examined the potential impact of the World Wide Web (web) in education. Owston (1997) offers a optimistic view of potential benefits of the today's web, utilizing a framework that emphasizes: (a) making learning more accessible; (b) promoting improved learning; and (c) containing costs. Fetterman (1998) reviews the tools currently available on the web (such as search, video conferencing, and file sharing) and suggests potential uses among educational researchers. Although these articles offer valuable advice about today's web capabilities, both authors acknowledge that the web is changing rapidly. Windschitl (1998) argues for more critical thinking and empirical studies about the ways in which web use in classrooms affects pedagogy and learning outcomes. They do not provide much guidance for educational researchers concerned with where the web is going, and how its trajectories of development may more fully meet educational needs. Such prospective information about emerging web technologies is important for the educational research community. In this report, we briefly highlight key trajectories of web development for learning communities, emerging from a national workshop devoted to the issues.

In late May 1998, we hosted a workshop on "Tools for Learning Communities" under the auspices of the National Science Foundation-funded Center for Innovative Learning 
Technologies (CILT, which is pronounced like "silt"), bringing together 115 leading researchers and developers from a balanced mix of 62 institutions, including universities, nonprofit organizations, corporations and schools. For example, corporate participants included IBM Global Education, Apple Computer, Netscape, Coopers-Lybrand, and many smaller firms such as NetSchools and Electric Schoolhouse. Academic and non-profit participants included researchers from the core four CILT partner institutions-SRI International, UC Berkeley, Vanderbilt University, and Concord Consortium—as well as organizations, universities and schools from all over North America. The innovative format of this workshop encouraged rapid information exchange, followed by brainstorming about educational issues and opportunities, and concluded with the formation of cross-institutional teams to seek innovations through partnership projects. Over the course of two days, the participants generated a wealth of ideas about the limitations of today's web, its near-term trajectories, and potential educational advances. We share a summary of those ideas here.

\section{What kinds of innovations are required?}

We will re-use the framework in Owston's article, which was based upon an address by Gordon Davies (1995) to organize the comments of our workshop participants on the limitations of today's web as regards advancing education. In addition, we will add a fourth question to the framework, based on Fetterman's (1998) article. Our account is somewhat more pessimistic about the utility of today's web tools for common-place learning needs, and oriented towards identifying possible innovations that might more closely connect educational infrastructure needs and the properties of technologies. 


\section{Can the web make learning more accessible?}

Today's web offers a primitive level of “accessibility": standard protocols provide conduits for information, Uniform Resource Locators (URLs) provide identifiers for particular pages, and search engines act as a primitive catalog of the available information. Based on this level, learning can be made available to students for whom distance or time are the primary impediments to success.

Our workshop participants, however, were quick to point out that distance and time are not the primary impediments to access to appropriate learning resources in K-12 education. Jim Kaput, for example, described the SimCalc Project, whose goal is to enable the majority of middle school students to master the core ideas of Calculus (http://www.simcalc.umassd.edu). Today's web facilities are not sufficient to accomplish this goal; even if inner city sixth graders could get raw access to a university calculus course through the web (such as http://www.temple.edu/ cow), it is doubtful that they could understand the presentation as it is offered to university freshman. Providing access to the idea of calculus means more than on-line access to yesterday's calculus texts; it means transforming the presentation of that subject matter to leverage the visualization, simulation, and modeling capabilities of advanced technology.

A related problem of access raised in the workshop was that interactive communication on today's internet is overly dependent on text. Students at the lower grade levels are not necessarily fluent readers, and are unlikely to be able to learn by participating in forums that require typing their thoughts as text. Similarly, standards for design of web materials to achieve "universal access" (e.g., for the blind) are in their infancy. And today's audio and video conferencing tools are not practical for typical classroom sizes of $20-30$ students, sometimes 40 . The tools of the office worker are not simply translatable to the classroom setting, as uses of desktop 
conferencing in distributed learning environments such as the CoVis Project

(http://www.covis.nwu.edu/) have indicated (Gomez, Fishman \& Pea, 1998; Pea et al., 1997). More broadly speaking, most of the available internet tools available are not robust and simple enough for use in average classrooms, where substantial time delays or setup difficulties can render a classroom unmanageable.

A final set of problems of access is the problem of too much access, of three sorts: (1) "access" to danger; (2) access to too much information (an overload without a good match to the learners' tasks), and (3) heavy exposure to advertising. As Marvin Weinberger of Electric Schoolhouse (http://www.electricschoolhouse.com) emphasized; students need a secure, private, safe place to learn, with vetted resources. The information overload problem is likewise serious: winnowing through thousands of hits from web searches during students' on-line research projects is not a very productive use of class time. Finally, the flood of advertising banners pouring into schools on web sites used by students can be viewed as an unprecedented classroom tool for pervasive corporate influence on children's consumer behaviors (Center for Media Education, 1996; for up-to-date information on this issue, see CME's web site at http:(/www.cme.org.).

\section{Can the web promote improved learning?}

Owston (1997) reviewed three ways in which the web can improve learning: (1) by appealing to the learning styles of students, presumably increasing their motivation to learn; (2) by offering greater convenience through asynchronous communications; and (3) by providing a fertile ground for developing high-order order thinking skills, which are required to overcome the general lack of organization of knowledge on the web. While our workshop participants would 
probably agree with these points, they raised some additional issues that present serious barriers to improving learning through the web as it is today.

The most commonly raised issue was the lack of integration of today's web with the structure of K-12 education. Very few web resources are indexed to curricula, state frameworks or national standards (see Gordin, Gomez, Pea, \& Fishman, 1996 for highlighting of this problem shortly after web browsers hit the classroom). Since these structuring documents guide efforts to improve and reform schooling, it is very unlikely that technology can achieve a large scale impact without tight coupling. Likewise, calls for increased accountability are a powerful force in educational reform, and most web resources lack integration with assessment tools.

Another key issue for our workshop participants was the difficulty of using today's web as at medium for constructivism, a predominant theory of learning based on the cognitive and social processes of constructing knowledge (Bransford, Brown, \& Cocking, in press). It is much easier to read, view and hear information on today's web than it is to create information. Indeed, the process of authoring or composing web content is not well-integrated into web browsers and information access tools, and requires mastery of a complex set of technical products and processes. Likewise, our workshop participants felt that the web was over-rated as a tool for collaboration. Some of the most important processes in collaboration, like the creation of shared beliefs and values, are hard to reproduce in the web environment. These processes are particularly important in teacher professional development, and currently require intensive faceto-face contact. Indeed workshop participants worried that the term "collaboration" is in danger of losing its meaning, as technology evangelists tend to label almost any web facilities for correspondence or coordination across distance as "collaboration tools." Inasmuch as we wouldn't call the US Post Office or the San Francisco Convention Center a "collaboration tool," 
we should be cautious about claiming that facilities for exchanging messages over the web are "collaboration tools."

Finally, our workshop participants were critical of the idea that the today's web, by itself, can foster higher-order skills such as problem solving, critical thinking, or teamwork. Even accomplished teachers are overwhelmed by the task of helping their students impose meaningful structure from information available over the web without additional tools to organize its raw, disorganized information into credible chains of argument or other rhetorical forms that could support learning. Several tools, discussed later in this article, provide a means of organizing information to better enable critical thinking about web resources.

\section{Can the web help contain costs?}

Although hardware and software purchasing, maintenance and support are expensive, our workshop participants focussed on two additional kinds of costs. First, the participants noted that many educational technology businesses that serve the K-12 market are failing. At the standard price of $\$ 1$ million to produce an interactive software offering, and the small profits possible in the educational market, very few companies have a stable business. Mergers and acquisitions. exemplified by The Learning Company's (TLC) acquisition of Broderbund, and the recent acquisition of TLC itself by Mattel, are evidencing the power of brand and the push to the commodification of educational technology. Even fewer educational software companies seem able to take on projects with significant research and development risk. Efforts to reduce production costs, such as the Educational Object Economy's work to amalgamate and coordinate the work of independent developers (http://www.eoe.org ), are required to reduce the costs of production and create new, more efficient distribution channels. Second, participants noted that 
the cost of identifying relevant resources on the web is much too high for overburdened teachers to undertake. Metadata, which labels web resources with additional annotations about the resource, is needed to tune searchers for educational content more tightly to the teachers' and students' needs (http://www.imsproject.org provides the current status of the EDUCAUSE consortium of academic, commercial and government organizations that is building "the internet architecture for learning”).

\section{Can the web improve research?}

Fetterman's (1998) article offers many suggestions about productive ways to use today's web tools in educational research. Although we value these suggestions, our workshop participants focussed on a qualitative difference between today's tools and their understanding of the difficulties facing researchers. Today's tools largely focus on autonomous publication of and anonymous access to research materials. Our workshop participants instead focussed attention on the need for infrastructure to support a "knowledge network" that unites related research projects in a collective effort to accumulate and disseminate knowledge more rapidly and widely (see Pea, Tinker, Linn, Means, Bransford, Roschelle, Hsi, Brophy, \& Songer, in press). Tools are needed, for example, to enable researchers to act collectively to: (a) assemble a shared annotated bibliography for their field, (b) coordinate the production of answers to "frequently asked questions" about their research area, or (c) produce an integrated tour of the leading innovations in their field. Such tools are in their infancy. Indeed, it is quite difficult to foster integration of research results across institutions and research projects toward any cumulative picture of the state of research knowledge on learning and technology. Yet more integration of research on technology in education is needed to achieve a wide impact on education as a whole, as 
emphasized in the 1997 PCAST report to the President on using technology to improve K-12 education.

\section{What kinds of innovations are possible?}

Our workshop included over 30 short presentations on recent developments in tools for learning communities. Although it is impossible to predict exactly where these developments will lead, these presentations suggest the vectors along which leading researchers and corporate developers are heading. In reviewing the presentations we identified three major clusters of presentations, which suggest the three change vectors which follow:

\section{Vector 1: Towards Shared Active Representations}

When two or more people are learning together face-to-face, or when one or more learners are engaged interactively with a mentor or teacher, there is a rich interchange of graphical and verbal representations, and gestures and pointing and linguistic reference to aspects of these representations are fundamental parts of the process of interpretation and making of meaning. These representations made during learning interchanges become "layered" rather quickly, as annotations and other markings — such as circles and underscores-are used to direct the attention of other participants.

Workshop participants discussed innovations that attempt to move beyond the shared whiteboards of many collaboration software environments to shared active representations which are subject-matter specific. These might include states of active simulations (in which control can be exchanged among remote participants), mathematical notations that are linked to graphs that plot their expressions, and layering of annotations on such simulations and notations. The 
messages that participants can construct need to be richer, with easy capacity for creating, editing, linking, and displaying drawings, equations, graphs, spreadsheets, and models. Participants were also concerned with understanding what is to be gained in the well-motivated use of shared video in these media-rich, networked, interpersonal workspaces. Research questions include: What kinds of notations should be available to collaborating learners? How can advanced visualization, simulation, and modeling tools be made to work with multiple students collaborating over the web? What kind of tools for shared control, mark-up, and annotation transform video from a representation which is passively watched to one which is actively utilized by learners (including teachers) in formulating, expressing, and critiquing ideas?

\section{Vector 2: Towards Advanced Socio-Cognitive Scaffolding}

Throughout history, great teachers have created participation structures and progressive sequences that engage learners in deep thinking, provide multiple viewpoints, support reflection, and offer frequent feedback and guidance toward higher standards. The Socratic dialogue offers one famous example in which students learn through progressive questioning from an expert. More recent social science and cognitive research has uncovered successful patterns in tutorial, mentoring, and group discussion interactions. Recognizing that typical internet chat and bulletin board systems do not organize conversation well for learning, researchers have created tools like CSILE (Scardamalia \& Bereiter, 1994), KIE (Linn, Bell, \& Hsi, 1998) and CoVis (Edelson, Pea \& Gomez, 1996) each of which "scaffolds" learning by pre-structuring the kinds of contributions learners can make, supporting meaningful relationships among those contributions, and guiding students' project inquiries on the basis of socio-cognitive principles. 
CILT participants were very interested in integrating the insights from these types of tools and related research into more widely available products. At the same time, we are aware that successful learning does not always fit the predefined categories supported in such tools, and does not always follow known patterns. Thus, we seek ideas for moving beyond the scaffolding of contributions and relationships, to tools that allow teachers and students to dynamically and reactively structure their history of interactions so as to maximize future learning opportunities. For example, we need the ability to capture a session history as students work with a shared representation, so that the session can later be replayed. Reflection on such an animated history can encourage higher-order learning in which students become aware of their own process of constructing knowledge. In addition, reviewing the history with a coach can probe critical incidents to spur deeper learning. Finally, histories might be packaged as case studies that enable others to learn more effectively. For example, a teacher might develop pedagogical insight by watching the condensed and annotated history of student interactions. How can we best capture and extract the critical moments from learning activities (video annotation, screen recording, semantic event analysis)? How can we re-use these traces to support deeper learning? How might tools support the dynamic, reactive, and re-constructive activities of expert tutors, mentors, and coaches?

\section{Vector 3: Towards Tools Which Foster Self-Improving Communities}

Our workshop participants indicated that tools for learning communities must move beyond forums for exchanging tidbits and opinions, to structures which rapidly capture knowledge-value and foster rapid accumulation and growth of a community's capabilities. Ideally the infrastructure for a learning community should be so designed that each contribution to the community spawns far greater value than the contribution itself costs to produce. 
One direction for innovation involves recommender systems, which can extract valuable information from the patterns of usage of internet resources. For example, by noticing which downloadable classroom activities are most often mentioned in a discussion forum, a recommender system might be able to help new teachers more quickly find the best resources in a vast archive. Another important direction involves tools to allow contributors to share partially completed resources, and enable others to improve upon them. A related direction is "knowledge mining" -- discovering efficient processes for quickly aggregating and collating the knowledge of a community on a particular topic.

Some of the opportunities for innovation include addressing these questions: How can technology better enable participants to find each other and form collaborative teams around mutual goals, skills, and work processes? What are some of the emergent properties of distributed learning communities, and how can we capture the value of these? How can products of the work of these groups and of CILT itself be captured and indexed for continuing value?

\section{The Role of the Center for Innovative Learning Technologies (CILT)}

CILT is a distributed center that is funded by the Knowledge and Distributed Intelligence program of the National Science Foundation (http://www.cilt.org ). Unlike most centers, which focus on synergies in an internal group of researchers, CLT acts as a catalyst within a growing network of external researchers and corporations. CILT aims to increase cross-institutional collaborations, harvesting and synthesis of research findings, and transfer from research into the commercial sector. 
At our workshop, Lou Pugliese, Chief Operating Officer of ETC of TCI described the potential of CILT by contrasting CILT's capabilities with industry's capabilities. CILT is talentbased, R\&D oriented, free of emotional ties to past products, capable of rapid prototyping of new innovations and of providing a neutral ground where partners can meet. Industry, on the other hand, has skill in brand creation, market outreach, rapid scale-up to huge audiences, abilities to cut through red tape, and robust service-oriented infrastructures. CILT, Pugliese argued, has the potential to bring together both sides, and enable more rapid translation of educational innovations into products with large-scale impact.

The results of our workshop gives some insight into how this process will occur. One result of the workshop was the production of rich scenarios for tools for learning communities. These scenarios were important as proxies for grounding design in the realities of learning environments. For example, Jim Kaput outlined a scenario in which a classroom was better served by a single workstation computer and a large set of inexpensive handheld devices than by every student having their own PC. A second result was the identification of key functionalities of tools which are as yet unmet by the marketplace. For example, several presentations converged on the need for search engines to produce stronger social cues (e.g., social information filtering according to aggregate use patterns from users of similar profiles), rather than purely informational displays. Finally, a diverse set of issues requiring further research were identified, ranging from the need for simpler interfaces to mechanisms for sharing best teaching practices in a learning community. Funding program officers were on hand and taking notes, which may translate into future requests for proposals that more closely match what workshop participants defined as the most important research issues. Similarly, many corporate participants were able to identify potential research partners from the workshop audience. 
CILT's role also extends beyond gathering the community to generate consensus on issues and to identify potential partners. In the second half of the workshop, participants self-grouped according to common interest and worked collaboratively to generate new proposals for partnership projects that could be seed-funded by CILT. Seven proposal concepts were generated, each bringing together a cross-institutional and inter-disciplinary group to work on a common vector of innovation. For example, one group will work to better inform technical standards organizations currently focussing on higher education and corporate training (such as EDUCAUSE's IMS Project) of K-12 educational needs. Such standards will eventually establish the base capabilities of all tools in the marketplace, and thus have a profound effect on the real world technologies available to schools. CILT was able to provide seed funding to five of the novel proposals generated at the workshop, and will seek to encourage the proposals forward through its relationship with funding sources as well as its Industry Alliance Program. The CILT process is an open one, and interested researchers should check our web site (http://www.cilt.org) for information on how to become involved at the annual conference to take place in San Jose, California, April 29-May 2, 1999.

\section{Conclusion}

Although the web may be attractive for some $\mathrm{K}-12$ and educational research projects now, we believe that there are major weaknesses which must be addressed by further innovation before the internet becomes a key tool for learning communities. Moreover, the internet five years from now is likely to be more different than today's internet is from prior bulletin board and conferencing systems. 
In educational research relating to technology, there are two broad classes of project goals.

One class focuses on recommending effective ways of utilizing today's resources. An alternative focuses on gaining insights and directing mutual evolution of technology innovation with pedagogical and curricular innovation. In the case of the internet, with its explosive rate of growth and change, we believe educational researchers should turn their focus to the latter, and seek partnerships and coalitions between corporations and researchers that can work to ensure that the parallel evolutions in technology and educational practice leads to better mutual fit.

\section{Acknowledgements}

CILT is funded by National Science Foundation grant \#CDA-9720384, which we gratefully acknowledge.

\section{References}

Bransford, J. D., Brown, A. L., \& Cocking, R. R. (Eds.). (in press). How people learn: Brain, mind, experience and school. Washington, DC: National Academy Press.

Center for Media Education (1996). "And Now a Web from our Sponsor': How Online Advertisers Are Cashing In On Children," infoActive (Washington: Center for Media Education), 2(2), 1-10. (http://epn.org/cme/infoactive/22/22nweb.html).

Davies, G. K. (1995, June). Higher education's big problems: Can technology help solve them? Keynote address at the semiannual meeting of the Educom National Learning Infrastructure Initiative, Keystone, $\mathrm{CO}$. 
Edelson, D. C., Pea, R. D., \& Gomez, L. M. (1996, April). The Collaboratory Notebook: Support for collaborative inquiry. Communications of the $A C M, 39,32-33$.

Fetterman, D.M. (1998). Webs of meaning: Computer and internet resources for educational research and instruction. Educational Researcher, 27(3), 22-30.

Gomez, L. M., Fishman, B. J., \& Pea, R. D. (1998). The CoVis Project: Building a large-scale science education testbed. Interactive Learning Environments, 6(1-2), 59-92.

Gordin, D., Gomez, L., Pea, R. D., \& Fishman, B. (1996, December). Using the World Wide Web to build learning communities in K-12. Journal of Computer-Mediated Communications, 2(3). (Now available at hrtp://www.usc.edu/dept/annenberg/vol2/issue 3/gordin.html. Earlier related reports by these authors appeared in 1995 at the now-defunct Global Network Navigator web site.)

Linn, M. C., Bell, P., \& Hsi, S. (1998). Using the Internet to enhance student understanding of science: The Knowledge Integration Environment. Interactive Learning Environments, 6(1-2), 438.

Owston, R. (1997). The World Wide Web: A technology to enhance teaching and learning? Educational Researcher, 28(2), 27-33.

PCAST (President's Committee of Advisors on Science and Technology). (1997). Report to the President on the Use of Technology to Strengthen K-12 Education in the United States. Panel of Educational Technology. (http://www. whitehouse.gov/WH/EOP/OSTP/NSTC/PC.AST/k12ed.html.) 
Pea, R.D., Gomez, L. M., Edelson, D.C., Fishman, B. J., Gordin, D. N., \& O’Neill, D. K. (1997). Science education as a driver of cyberspace technology development. In K. C. Cohen (Ed.), Internet links for science education (pp. 189-220). New York, NY: Plenum Press.

Pea, R.D., Tinker, R., Linn, M., Means, B., Bransford, J., Roschelle, J., Hsi, S., Brophy, S., \& Songer, N. (in press). Toward a learning technologies knowledge network. Educational Technology Research and Development..

Scardamalia, M., \& Bereiter, C. (1994). Computer support for knowledge-building communities. The Journal of the Learning Sciences 3(3), 265-283.

Windschitl, M. (1998). The WWW and classroom research: What path should we take? Educational Researcher, 27(1), 28-33. 